\title{
Impact of the Sun and its Risk of Cancer
}

\author{
Jorge Ocampo-Candiani* and Sonia Chávez-Alvarez
}

Departamento de Dermatología, Facultad de Medicina, Hospital Universitario Dr. José Eleuterio González, Universidad Autónoma de Nuevo León (UANL), Nuevo León, México

In this edition, the article entitled "Knowledge, attitudes, and practices on the use of sun protection in $6^{\text {th }}$ year medical students of two schools in the Peruvian Lambayeque region" is presented. In it, the authors take us through the study carried out on students in their last year of medical school. This article makes us reflect on what attitudes and actions our young doctors are taking regarding sun protection. Surprisingly, it is not $100 \%$ of the population of young physicians who know the harmful effects of photo exposure accurately, neither do they actively use measures to counteract the photodamage. It is our duty to participate and support the dissemination of knowledge regarding sun protection.

Sunlight should not be classified as entirely harmful since it participates actively in the cycle of terrestrial life, it is necessary for the photosynthesis of plants, and also plays a fundamental role in the cycles of wakefulness and sleep. In humans, it also has other positive effects such as the production of Vitamin D3 and stimulation of melanin production and also has a therapeutic value in certain pathologies such as psoriasis, vitiligo, and eczema.

We are all exposed to radiation. However, we are not all aware of the magnitude of the effects it can have on our skin. Ultraviolet radiation is divided into UVA (315-400 nm), UVB (315-280 nm), and UVC $(100-280 \mathrm{~nm})^{1}$. The atmosphere can absorb all the radiation caused by UVC, most of the UVB, but it gives us little protection against UVA'. Despite this, the participation of $80 \%$ of UVB and $20 \%$ of UVA is required for a sunburn to appear².

The population in Latin America usually presents darker phototypes. However, this does not mean that the photoprotection measures in these patients should be neglected. It has been found that the population with phototype III develops sunburns after 20 min of sun exposure and the population with phototype $\mathrm{V}$ usually requires up to $1 \mathrm{~h}$ of exposure, making them more susceptible to unintended photodamage ${ }^{2}$. Another important fact is that $77 \%$ of the solar radiation, we receive in the Northern Hemisphere, occurs between March and October ${ }^{2}$. The pediatric population has greater solar exposure than the adult population. It is estimated that during the first 18 years of life, they have received from $50 \%$ to $80 \%$ of the ultraviolet (UV) radiation to which they will be exposed in their lifetime ${ }^{1}$. A greater solar exposure in this stage is makes them more likely to develop melanocytic nevi and melanoma in adulthood 1 .

The present study mentions that "medical students do not apply it to themselves, which would show that in reality they are not convinced of this practice of skin cancer prevention." In other studies carried out concerning photoprotection, it has been found that only $39 \%$ of the subjects have used photoprotectants at some time. Furthermore, $26 \%$ of the subjects also came to consider that having a tan is healthy ${ }^{3}$. These preventive measures should be reinforced for the whole population in general. There is also a difference in taking preventive measures regarding gender, with women having the greatest adherence to photoprotection ${ }^{2}$. Regarding

\section{Correspondence:}

Jorge Ocampo-Canidani

E-mail: jocampo2000@yahoo.com.mx
Date of reception: 25-06-2018

Date of acceptance: 10-07-2018

DOI: 10.24875/RMU.M18000015
Available online: 01-10-2018

Medicina Universitaria. 2018;20(2):66-67

www.medicinauniversitaria.org CC BY-NC-ND license (http://creativecommons.org/licenses/by-nc-nd/4.0/). 
education, people with a university level of education are more likely to use photo protectors than those who do not ${ }^{3}$. This population recognizes that sun exposure can cause cutaneous neoplasms that can have a fatal outcome. The notion that this exposure also causes skin aging is present. However, in this same study group, $26 \%$ of the subjects rated having a tan as healthy ${ }^{3}$.

UVB rays alter the DNA of skin cells conferring cytotoxicity and mutagenic properties. UVA rays generate oxidative stress which also affects the DNA ${ }^{1}$. The acute effects of solar radiation are cutaneous erythema, hyperpigmentation, delayed tanning, epidermal hyperplasia, and the formation of free radicals ${ }^{1}$. Adverse effects that are classified as chronic UVR are mainly due to the light spectrum between 290 and $400 \mathrm{~nm}$ of UV length ${ }^{3}$. These chronic effects of radiation include photoaging, immunosuppression, photodermatosis, and photocarcinogenesis. Non-melanoma skin cancer (basal cell and squamous cell carcinoma) is the most frequent and develops from the cumulative UV radiation exposure ${ }^{3}$. Melanoma is related to short and intense exposures to sunlight, mainly during childhood.

The general recommendation is to avoid sun exposure between the hours of 10 am and $4 \mathrm{pm}$, use clothing that helps us cover the photoexposed areas as well as sunglasses, hat, or a $\mathrm{cap}^{2}$. Last, but not least, the application of photo protector should be with a schedule. the application of photoprotection should be every 2 to 4 hours; these include organic and inorganic filters. Organic filters can contain aminobenzones, cinnamates, octocrylene, salicylates, benzophenones, and avobenzone. The inorganic filters protect against ultraviolet light additionally and are those based on titanium dioxide and zinc oxide ${ }^{1}$. Benefits from sunscreen derive from its use and reapplication.

It is of vital importance to continue studies in this field because the more we know about the habits and knowledge of photoprotection in the general population, the better the measures and campaings that we can implement to raise awareness among the general population. To instruct all patients in photoprotection is a duty all physicians should have. All branches of medicine from pediatrics to geriatrics should continue to practice medicine based on the prevention of pathologies.

\section{References}

1. Arellano Mendoza I, D AP, Barba Gómez J, et al. Recomendaciones clínicas para la fotoprotección en México. Dermatol Cosmét Méd Quir. $2014 ; 12$.

2. Castanedo Cázares JP, Torres Álvarez B, Sobrevilla Ondarza S, Ehnis Pérez A, Gordillo Moscoso A. Solar exposure time for sunburn in mexican population. Gac Med Mex. 2012;148:243-7.

3. Castanedo-Cazares JP, Torres-Alvarez B, Medellín-Pérez ME, Aguilar-Hernández GA, Moncada B. Knowledge and attitudes of mexican population concerning solar radiation. Gac Med Mex. 2006;142:451-5. 